\title{
MÉXICO: ¿FIN DE LA “DEMOCRATURA”?
}

\section{Philippe Dautrey ${ }^{1}$}

Resumen: A raíz de la Revolución mexicana (1910-1917) se instauró una dictadura «suave» bajo la forma de un régimen corporativista. Además de la hegemonía del poder político, se caracterizó por el clientelismo y la corrupción endémica; todo lo cual marcó la cultura política. Por su parte, las tímidas reformas implementadas a partir de los años setenta y, sobre todo, el auge del neoliberalismo y la alternancia en el año 2000 dieron pie a una «democratura» cuyo rasgo principal fue la subordinación del Estado al mercado. No desparecieron las estructuras del viejo corporativismo, a las que se adaptaron los partidos admitidos a competir en las elecciones. No fue hasta julio del 2018, con la llegada a la presidencia del país de un movimiento social creado unos años antes y convertido en partido, cuando ocurrió la transición a la democracia liberal. La noción de ciudadano empezó a ser una realidad. Sin embargo, ¿se aleja definitivamente México de la sombra de la dictadura?

Palabras clave: México; cambios políticos; democracia; sociedad; cultura

${ }^{1}$ Universidad Autónoma de Zacatecas (México) dauphil@hotmail.com 
Abstract: In the wake of the Mexican revolution (1910-1917) a "soft" dictatorship in the form of a corporatist regime was established. Besides being based on the predominance of political power, it was characterized by clientelism and endemic corruption, all of which left its mark on the political culture. On the other hand, the limited reforms implemented since the 1970s and, in particular, the rise of neoliberalism and the replacement of the party in power in 2000 led to a pseudo-democracy whose main feature was the subordination of the State to the market. The structures of the old-style corporativism remained in place and the new parties allowed to compete in elections followed suit. It was not until July 2018, when a new social movement founded a few years before and changed into a party came to power, that a transition to liberal democracy occurred. Citizenship began to become real. However, is Mexico once and for all moving away from the shadow of dictatorship?

Key words: Mexico; political changes; democracy; society; culture

Resum: Arran de la Revolució mexicana (1910-1917) es va instaurar una dictadura «tova» sota la forma de un règim corporativista. A més de l'hegemonia del poder polític, aquesta es va caracteritzar pel clientelisme i la corrupció endèmica; tot això va deixar empremta a la cultura política. Por la seva part, les tímides reformes implementades a partir de la dècada de 1970 i, sobretot, l'auge del neoliberalisme i l'alternança l'any 2000 van portar a una «democratura», el tret principal de la qual va ser la subordinació de l'Estat al mercat. No van desaparèixer les estructures del vell corporativisme, a les quals es van adaptar els partits admesos a competir en les eleccions. No va ser fins el juliol de 2018, amb l'arribada a la presidència del país d'un moviment social creat pocs anys abans i convertit en partit, que va tenir lloc la transició a la democràcia. La noció de ciutadà va començar a ser una realitat. Malgrat tot, ¿s'allunya Mèxic definitivament de l'ombra de la dictadura?

Paraules clau: Mèxic; canvis polítics; democràcia; societat; cultura 


\section{Introducción}

En América Latina, las democracias que siguieron a las dictaduras nunca fueron totalmente representativas. Fueron herederas de las mismas "cuando no sus prisioneras" (Rouquié, 2011: 15). Uno podría denominarlas con el neologismo de "democraturas". No obstante, en el caso de México el régimen corporativista autoritario no nació de un golpe de Estado sino de la revolución que tuvo lugar entre 1910 y 1917. No es considerado como una dictadura en el léxico político local. Más bien es calificado de "dictablanda"; un autoritarismo moderado en algún modo (Rouquié, 2011: 130).

La democracia consta de tres dimensiones esenciales que se completan y son interdependientes: respeto a los derechos fundamentales, ciudadanía y representatividad de los dirigentes (Touraine, 1995: 43). En realidad, tal concepción se refiere a la tradición liberal. Se enfoca en la igualdad jurídica, pero es reticente en lo referente a la desigual distribución del poder político y económico. (De ahí que la pretensión de la economía de ser una ciencia esté firmemente arraigada en la necesidad de eludir toda responsabilidad por sus insuficiencias y sus injusticias). Impulsa la división de poderes para civilizar el gobierno mas sólo ha logrado dividirse en la misma medida en que frente a él existe un poderío económico muy potente. Este solamente acepta el imperio de la ley cuando no le perjudica (Galbraith, 2011: 138 y 148; Fernández Liria y al., 2017: 60). Esas contradicciones pautaron los ciclos políticos en América Latina.

En este subcontinente la democracia, cuya ampliación siempre les ha aparecido a las élites como una amenaza, apareció tarde. Las independencias se limitaron a una suerte de "Ilustración a sablazos". Prosperaron los caudillos, labrándose feudos regionales en un contexto de descomposición del Estado colonial y de precariedad institucional. A la postre, las sociedades se estructuraron en forma particular dando pie a democracias sin ciudadanos (Rouquié, 2011: 52, 53 y 111). En ellas, el poder político sojuzgó las esferas económica, 
científica, religiosa, etc. y restringió su autonomía. La sombra de la dictadura no dejó de rondar.

En México la recién llegada a la presidencia de un movimiento social creado unos años antes y convertido en partido auguró la transición a la democracia liberal. (El reemplazo del Partido Revolucionario Institucional -PRI_, que llevaba setenta y un años al mando, por el conservador Partido de Acción Nacional -PAN- en el año 2000 no significó sino un relevo de los dirigentes). Emergió una nueva cultura política, esto es, una matriz consciente o inconsciente que da significación a las creencias y al comportamiento de los ciudadanos (Castro Domingo, 2008: 217). La manera cómo la sociedad se concibe a sí misma cambió ${ }^{2}$.

Es a partir de esas premisas que se desarrollará el presente trabajo. Primero se analizará en qué consistió el régimen autoritario. Luego se abordará el periodo de "democratura" que le siguió. Por último, se examinará la Cuarta Transformación en curso, en tanto vector del giro democrático.

\section{El régimen autoritario}

\subsection{El dominio de la política}

La herencia colonial impregnó las instituciones latinoamericanas y aclara en buena medida su forma. No se disipó como por encanto, al producirse las independencias. Para las élites blancas, éstas representaron la aspiración a gobernarse ellas mismas, emancipándose de la metrópoli. Promulgaron constituciones que refrendaron su dominación. Para justificarla, apelaron a la razón -la única que tenía el derecho a gobernar- y a la capacidad (la facultad de votar aseguraba la preponderancia de los “mejores"). Acapararon todo el poder en desmedro de la soberanía del pueblo, la que reivindicó el México Morelos. En verdad, pretendieron beneficiarse de la legitimidad del voto popular sin correr los riesgos de la igualdad. Conciliaron la

\footnotetext{
${ }^{2}$ Ello remite a lo político, que se opone a la política entendida como la vida diaria de las instituciones, la competencia por el poder y sus avatares (Fernández, Lesgart, 2008: 38 y 40; Caillé, 2009: 126).
} 
retórica de la democracia representativa y la exclusión (Rouquié, 2011: 24, 42 y 43).

La conflictividad explica también el giro hacia posiciones de gran prudencia (preocupación por la excesiva democracia, freno a las mayorías y centralización, necesidad de liderazgos fuertes), tal como lo aconsejaba Bolívar a la hora de discutir las cartas constitucionales ${ }^{3}$ (Funes, 2014: 34). En efecto, los caudillos (los señores del desorden) pusieron el orden en tela de juicio hasta bien entrado el siglo XX. Uno fundado en la capacidad terminó por suplantar a la república utópica enarbolada por los próceres de la independencia. Garantizó la reproducción social, que era más importante que la producción económica. Se cristalizó en repúblicas sin ciudadanos, caracterizadas por la naturaleza étnica de las estructuras sociales, la concentración de la propiedad y el débil imperio de la ley (Rouquié, 2011: 47 y 71; Funes, 2014: 103). En definitiva, la modernidad liberal supuso la confrontación de una minoría de individuos "ilustrados" con una sociedad compuesta de actores (comunidades indígenas, haciendas, pueblos, clientelas y clanes) del antiguo régimen colonial (Rouquié, 2011: 46). Un atributo distintivo del liberalismo mexicano fue, sin embargo, su radical agrarismo y la creación de un espacio público despojado de la pujante competencia de la Iglesia, pero esto no incluía el reconocimiento del otro - diferente o pobre- como semejante e igual (Rouquié, 2011: 78 y 343; Funes, 2014: 60 y 61).

El régimen corporativista autoritario que siguió a la revolución mexicana no quebró el orden existente pese a que la Constitución de 1917 instituyo derechos sociales y soberanos muy adelantados (Funes, 2014: 110). Por el contrario, la necesidad de superar las rivalidades para sacar al país del caos después de casi un decenio de conmoción favoreció el autoritarismo. El partido dominante —el Partido Nacional

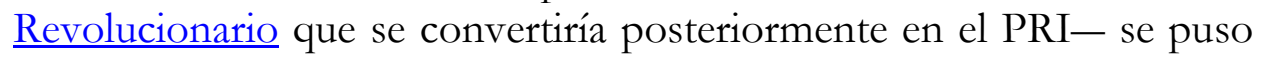
a las órdenes del omnipotente presidente, apropiándose el legado

\footnotetext{
3 El libertador decía que el sufragio censitario era "el primer dique a la licencia popular". Como en la concepción ateniense, el verdadero ciudadano es aquel que tiene la capacidad de ser elegido y de gobernar (Rouquié, 2011: 25).
} 
revolucionario y encargándose de la organización de la sociedad. No estuvo destinado a ganar las elecciones en una competencia democrática sino a escoger en su seno a los titulares del poder ${ }^{4}$. Sentó su hegemonía en una maquinaria de control que integró tanto a las asociaciones campesinas como a los sindicatos obreros y a los sectores marginados urbanos mientras su legitimidad se basaba en la distribución de recursos. A pesar de todo, esa "dictablanda" aseguró la ejemplaridad de la fachada democrática. Toleró una competencia política en dosis homeopáticas. Salvo en caso de crisis grave como los movimientos estudiantiles del 1968 y sociales en la década de los setenta, el fraude electoral - la manipulación de los electores, de los votos o de los resultados del escrutinio- y la cooptación reemplazaron la coerción generalizada (Rouquié, 2011: 118, 130 y 149; Funes, 2014: 116).

La democracia es ante todo un Estado de derecho en el que el Ejecutivo no invade todo el espacio institucional (Rouquié, 2011: 273). Empero, en el corporativismo la presidencia y la burocracia incorporada al partido hegemónico, en contubernio con las burguesías dueñas de las principales riquezas del país, se diseminan de manera extra-política e imponen su lógica a toda la sociedad. Ésta se estructura en torno a aquellas (Mascareño, 2010: 141). No hay una forma de dominación legal-racional y las fallas en el acoplamiento entre el poder político y la ley no son pocas. No es asegurada la garantía de los derechos fundamentales ni determinada la división de los poderes. Por tanto, el Congreso de la Unión —el parlamento mexicano- no era sino una cámara de registro. La justicia estaba puesta al servicio del PRI, al cual ninguna institución estuvo en condiciones de hacerle contrapeso.

\subsection{Los cimientos del corporativismo}

El que el corporativismo no sirviera por igual para todos (al contrario, miembros de comunidades originarias y habitantes de zonas

\footnotetext{
4 Por ejemplo, los diputados elegidos de manera proporcional no estaban vinculados a una circunscripción. (Todavía no lo están). No tenían que rendir cuentas a sus electores. Sólo dependían del partido o del gobernador.
} 
marginadas no fueron incluidos como ciudadanos con plenos derechos) indujo al clientelismo, es decir, la generación de lazos personales fuentes de favores y de seguridad con el poder político. La máquina del partido hegemónico o un cacique hacen atribuir bienes o servicios, que dependen del mercado o son en principio accesibles a todos según criterios universalistas, a cambio de voto. Éste se convierte un bien intercambiable. No depende tanto de la opinión del elector como de la ayuda dispensada. La una se confunde con la otra. En rigor, lo garantizado por la ley es impersonal por definición. Ofrece menos dividendos políticos que la relación clientelar, la cual circunscribe también la agitación social (Rouquié, 2011: 78 y 86). Asimismo, la insuficiencia de los servicios públicos y una administración entorpecida y corrompida hacen indispensable al intermediario. A la hora de conseguir un empleo en el sector público, un individuo no llega a nada si no tiene conexiones. La vía meritocrática es minoritaria (Rouquié, 2011: 80).

La corrupción en las esferas pública, privada y sindical era lo habitual. En el corporativismo, existe de facto una distorsión entre el país legal y el país real. La conciencia normativa está poco afianzada. Una regla informal se aplica discrecionalmente. El legalismo de las formas es más importante que la realidad de las prácticas (Basave, 2011: 58 y 92; Rouquié, 2011: 89 y 192).

El clientelismo y la corrupción no sólo estructuraron el campo de acción de los ciudadanos, sino que condicionaron su cultura política. La conformó igualmente el miedo que destilaba el poder político a través de la represión a los opositores, cuyo objetivo era amordazar los conflictos de clase y despolitizar a la sociedad. (Si bien utilizaba la violencia, como durante la masacre de estudiantes contestatarios en 1968, para alejar la amenaza que las demandas democráticas hacían pesar sobre sus intereses, recurría con frecuencia a la negociación extralegal). (Basave, 2011: 44; Rouquié, 2011: 78 y 183). En pocas palabras, no estaba permitido cambiar de manera institucionalizada al régimen. Seguir la norma del PRI era algo que así debía de ser (Castro Domingo, 2008: 231). No estaba ausente la dimensión mítica, o sea, la invocación de una masa de símbolos y 
creencias (véase en Cassirer, 1997: 7 y 31). En vez de apelar a ciudadanos representados por el Estado en sus derechos fundamentales, el mito se dirigía a sujetos, exhortando la identidad a la revolución mexicana ${ }^{5}$ y sus principios fundacionales así como al pasado idealizado de los pobladores originales. Semejante cultura creó vínculos de identificación más que de representación (Fernández, Lesgart, 2008: 40-41; Rouquié, 2011: 258; Funes, 2014: 21).

\section{La "democratura"}

\subsection{El ascenso del mercado}

A partir de mediados de los años setenta se pusieron en marcha modestas reformas. Aumentó la dosis de proporcionalidad para permitir cierta representación de las minorías. El objetivo era evitar el incremento de demandas desestabilizadoras y asegurar la supervivencia del régimen. Por su parte, la negociación con el conjunto de las fuerzas políticas en la década de los noventa desembocó en la promulgación de un código electoral y en la creación de un instituto electoral supuestamente independiente. Se pretendía proporcionar mayor transparencia a los escrutinios (Rouquié, 2011: 131-132). De hecho, el apoyo de las asociaciones campesinas y del sector popular de la economía subterránea, que constituían la clientela masiva en la que solía abrevarse el corporativismo, empezaba a deteriorarse. En cuanto a la corrupción que afloró con ocasión del sismo en 1986 y al fraude en las elecciones dos años después, desgastaron aún más la credibilidad del PRI.

A la sazón, el mismo abandonó el dirigismo estatal y el desarrollo hacia adentro por el neoliberalismo. (Se separó la corriente izquierdista nacional popular, de la que procede el presidente López Obrador). Convirtió al Estado en promotor del mercado

\footnotetext{
${ }^{5}$ El mito de la revolución se levantó sobre la idea de una fusión entre el pueblo mexicano y el gobierno revolucionario. La cultura política se encontró ceñida por el poder y se produjo sujetos (Bartra, 2005: 14 y 215).
} 
autorregulado, de la apertura comercial ${ }^{6}$ y de la desestatización. Una matriz dedicada a servir la rentabilidad del capital financiero y valorizar la mano de obra barata sustituyo a la matriz Estado-céntrica que caracterizó al viejo régimen (Guillén Romo, 2005: 191-204; Calderón Rodríguez, 2011: 45; Dautrey, 2018: 83). A la par, se debilitó el encuadramiento protector del corporativismo. El combate a la pobreza se limitó a los grupos más desprotegidos mientras se recortó el de por sí limitado sistema público de bienestar. (Por ejemplo, se privatizó el Instituto Mexicano del Seguro Social, pasando de un esquema de pensiones por reparto a otro por capitalización). La sociedad se estructuró cada vez más desde el mercado, esto es, el dinero y su lógica operativa (Polanyi, 2001; Mascareño, 2019: 30). El consumo y su creditización fueron llamados a integrar a todos los ciudadanos.

Lo anterior participó de la llegada a la presidencia del PAN que, durante sus dos sexenios (de 2000 a 2012) al mando del país, continuó adaptando las estructuras corporativistas a los requisitos del neoliberalismo. En particular, procuró desmantelar todavía más los amortiguadores sociales implementados desde el sexenio cardenista (1934-1940), cuando se reforzó el dirigismo estatal (Rouquié, 2011: 265; Funes 2014: 170-171). Al regresar el PRI al poder en 2012, no puso en tela de juicio ese rumbo ideológico. Importantes franjas de la sociedad se marginaron o perdieron posiciones en el consumo por la vía de aumentos en el desempleo y por la reducción del salario real (Dautrey 2018: 84-86).

El tímido proceso de democratización y la alternancia no constituyeron una amenaza sobre los poderes económicos que se gestaron en el periodo autoritario. Más bien, acrecentó su predominio y capacidad de injerencia y decisión. Tras la escena pública de la soberanía popular, la escena privada con arreglo a la correlación de fuerzas reales se extendió por el poder político. A semejanza del resto

\footnotetext{
${ }^{6}$ Se firmaron un sinnúmero de tratados de libre comercio, de los cuales el más importante fue el ex Tratado de Libre Cambio de América del Norte, ahora TMEC.
} 
del continente, aumentó el grado de oligarquización del Estado (Osorio, 2004: 177-178).

\subsection{Las trabas a la democracia}

En el corporativismo, la intermediación discrecional de los jefes y caciques en el vínculo de los ciudadanos con las instituciones era la pauta (Merino, 2003: 124). Se generó una normativa extralegal que fomentó la demanda particular y desgastó la confianza hacia ellas. Sin embargo, uno no se libera del pasado sin reformas en profundidad y por la sola alternancia. Con el arribo del PAN al poder en el año 2000, no recuperaron su legitimidad (Castro Domingo, 2008: 198 y 207; Rouquié, 2011: 189). Por el contrario, las reglas informales del clientelismo siguieron rivalizando con la legalidad. Los nuevos dirigentes reanudaron las prácticas poco permeables a la democracia, en un marco moldeado por y para el régimen corporativista. El que no dudaran en aliarse con el poderoso sindicato de los docentes para ganar las elecciones presidenciales, a cambio de dejar a su lideresa ejercer su influencia sobre la Secretaría de Educación, fue un presagio (Rouquié, 2011: 150-151). Por añadidura, redujeron la solidaridad y la protección social gubernamentales, aminorando los estímulos hacia los canales institucionalizados para acceder a los beneficios y atomizando las lealtades hacia las colectividades (Calderón Rodríguez, 2011: 296; Dautrey, 2013).

Tampoco se abatió la corrupción, desde la "mordida" exigida al automovilista por los agentes de tránsito o los funcionarios, hasta la protección a actividades delictivas como el crimen organizado garantizada por los jefes y la corruptela en el ámbito de la justicia. (A mediados de la década pasada, concernía a entre el cincuenta y el setenta por ciento de los jueces). Así, no resulta extraño que las condiciones de legalidad como la impunidad y la violación a los derechos humanos ubicaran a México por debajo del promedio latinoamericano (Calderón Rodríguez, 2011: 183). Todavía otras formas ganaron protagonismo. En primer lugar, el tráfico de influencias y el saqueo al erario púbico se dispararon en favor de los consorcios privados más influyentes. Estos consolidaron sus nexos 
con los tecnócratas, que venían reemplazando a los políticos de la vieja guardia. Mediante acuerdos obtuvieron enormes recursos públicos ${ }^{7}$ (Babb, 2003: 239; González Gómez F. y M-A, 2007: 371-373; Castro Domingo, 2008: 198). En segundo lugar, la correlación de fuerzas entre los cuerpos de seguridad y las organizaciones criminales del tráfico de droga empezó a modificarse. La subordinación a la que el régimen autoritario las sometía se erosionó. Tales organizaciones se extendieron por zonas donde su presencia anterior era escasa (González Gómez F. y M-A, 2007: 373; Garay Salamanca, SalcedoAlbarán, 2012: 234 y 241). Simultáneamente, aumentaron su capacidad de corrupción e influencia y buscaron cooptar al Estado. Para ellas, no es el enemigo sino el instrumento. Nada sucede sin una conexión entre ambos. Dicho esto, este fenómeno era aún restringido en comparación con aquellos como el soborno y la intimidación. Por último, las actividades ilegales como el negocio masivo de la piratería o la explotación y tráfico de recursos minerales crecieron (Garay Salamanca, Salcedo-Albarán, 2012: 137, 161, 225 y 301).

Por otro lado, se observó una evolución de la cultura política. El fundamentalismo de mercado, con su imperativo de circunscribir la ciudadanía al consumo, y las campañas mediáticas en contra de los movimientos sociales debilitaron las identidades políticas y las ideologías que las conformaban (Bihr, 2017; Rouquié, 2011: 325 y 326). En lo que concierne a la globalización y la reducción del ámbito del Estado, mermaron el sentido de participación en las instituciones nacionales (Cappello, De Pedro Robles, 2010: 23 y 43). Al mismo tiempo surgieron reivindicaciones relativas al derecho a tener derecho, vinculadas a la identidad sexual y a la exclusión (Dautrey, 2018: 89).

\footnotetext{
${ }^{7}$ En los noventa, se dio el caso más sonado: el Fondo Bancario de Protección al Ahorro. Los banqueros, en complicidad con los funcionarios de la Secretaría de Hacienda, integraron todo tipo de operaciones de crédito fraudulento y de origen irregular a las operaciones acreditadas. Luego, sus deudas y las de otros sectores privados se transformaron en deuda pública (González Gómez y González Gómez, 2007: 313-319). En este caso, la corrupción favoreció la intervención de los poderes económicos en la formulación de políticas públicas.
} 
Pero no retrocedió la tendencia a tratar al adversario político como enemigo. Las campañas sucias en contra del entonces candidato López Obrador en las elecciones presidenciales del 2006 y 2012 fueron un indicador de ello.

\section{La Cuarta Transformación ${ }^{8}$}

\subsection{El freno a la deriva neoliberal}

La alternancia del año 2000 resultó ser un relevo de los dirigentes. No hubo un cambio de régimen y las políticas neoliberales se mantuvieron (González Gómez F. y M-A, 2007: 331 y 362; Batres Guadarrama, 2017). ¿Por qué en la actualidad se puede hablar de transición a la democracia?

En una democracia de tipo liberal, cualquier partido puede ejercer la representación de la ciudadanía y ser elegido. Eso no ocurrió durante el periodo autoritario y la "democratura". Los partidos de oposición que se proponían cambiar el régimen político estaban vetados o bien sufrían fraudes electorales, tales como en 1988, en 2006 y muy probablemente en 2012. En contraste, por primera vez desde la revolución mexicana uno de estos partidos (el Movimiento Regeneración Nacional, o Morena) llegó a la presidencia en julio de 2018, consiguiendo el 53,19 por ciento de los votos, es decir, unos 31 puntos más que el candidato en el segundo puesto (INE, 2018). Con tales cifras, no fue posible recurrir al fraude. La aguerrida maquinaria electoral al servicio del PRI y del PAN no pudo con este partido que se creó primero, a principios de la década, como movimiento social. (Impulsado por el actual presidente López Obrador, constituyó un espacio crítico y de movilización). Sobre todo, el PRI y el PAN se encontraban desacreditados desde mucho tiempo atrás por su

\footnotetext{
${ }^{8}$ López Obrador llama Cuarta Transformación a su proyecto en referencia a tres cambios clave en la historia de México: la Independencia (el movimiento armado de 1810 a 1821 para liberarse de los trescientos años de dominio español), la Reforma (la guerra entre liberales y conservadores de 1858 a 1861, tras la cual surgieron las Leyes de Reforma como la separación de la Iglesia y el Estado) y la Revolución (entre 1910 y 1917, al final de la que se promulgó la Constitución que rige actualmente el país).
} 
comportamiento patrimonialista y su corrupción endémica (Cappello, De Pedro Robles, 2010: 27).

Algo cambió en materia de cultura política. Si bien el autoritarismo implantó un muy enraizado sentimiento de impotencia para incidir en las decisiones gubernamentales, a partir de la alternancia el electorado popular comenzó a creer en la potestad del voto. Dejó de ser un ritual sin alcance como en el pasado. En amplios grupos sociales, se forjó un sentido de representatividad (Castro Domingo, 2008: 204 y 231-232). Dicho de otro modo (Fernández, Lesgart, 2008: 20), los lazos que comunican a los ciudadanos con el poder político ya tienen sentido. En efecto, el proyecto que persigue la Cuarta Transformación es compartido por una mayoría de ellos, y el nuevo gobierno estimula la democracia participativa y el control ciudadano sobre los gobernantes. A comienzos del año 2019, aprobó la reforma a la Constitución sobre las consultas populares ${ }^{9}$ y la revocación del mandato.

Ahora bien, la Cuarta Transformación no abjura del capitalismo sino de su variante neoliberal, a la que se imputa el estancamiento de la economía, la desigualdad y la pobreza en la mayoría de la población. Empero, la reiterada exhortación a poner fin a la deriva neoliberal no deja de ser un ponderado cuestionamiento al Consenso de Washington (que promueve la liberalización del comercio exterior y del sistema financiero, así como la limitación de la intervención estatal). Por cierto, el capital financiero logró escapar del marco legal que los Estadosnación le imponían y ellos se encuentran hoy en una posición de debilidad para incidir en él ${ }^{10}$ (Bauman, 2007: 103; Castro Domingo, 2008: 205; Therborn, 2014: 13). Eso dificulta el regreso a un Estado interventor y a la re-estatización de las empresas desnacionalizadas. Por otra parte, la participación de los empresarios es fundamental para

\footnotetext{
${ }^{9} \mathrm{Y}$ se realizaron dos relacionadas con grandes obras de infraestructuras de transporte.

10 En cambio, el capital financiero ejerce toda su influencia sobre el nuevo mandatario. Las agencias calificadoras privadas Moody's y Fitch redujeron la calificación de Petróleos Mexicano mientras que la producción de crudo va en aumento.
} 
conservar la estabilidad económica e impulsar el desarrollo (Morena, 2011 y 2018/a). Así pues, el gobierno mantuvo la autonomía del Banco de México y estableció la austeridad en la administración pública federal con rango de ley, redimensionándola (Morena, 2018/a). Se limitó a poner un alto a las privatizaciones y revisó la validez de las concesiones de las mineras y de Petróleos Mexicanos, la mayor empresa nacional, privatizada en 201311. Asimismo, a raíz de la primera consulta popular, canceló la construcción del Nuevo Aeropuerto Internacional de la Ciudad de México. A la vez, sancionó la corrupción, los daños al medio ambiente y la violación a los procedimientos jurídicos que caracterizaban esta mega-obra. De forma paralela, busca detonar el desarrollo productivo de los estados empobrecidos, particularmente en el sur y sureste del país. Prevé crear en diecinueve de ellos 400 mil empleos permanentes en la pequeña y mediana agricultura por medio del programa Sembrando Vida, incluyendo siembra de árboles frutales, maderables y de cultivos de ciclo corto (Morena, 2018/c). En la sureña Península de Yucatán se construirá una línea ferrocarril —el Tren Maya - destinada a fomentar el turismo y la economía local.

En definitiva, la transformación en proceso lleva el sello de la tradición nacional popular, de la que López Obrador es heredero. La clase es equiparada al pueblo. El único conflicto dable se da entre éste y la oligarquía corrupta. La referencia a la corrupción subsume la referencia a la lucha de clase y al capitalismo. De hecho, la nova lingua neoliberal ha invertido y obliterado el significado de los conceptos de los grandes meta-relatos venidos a menos. Referirse a ellos es políticamente incorrecto, siendo lo "correcto" sólo los marcos de pensamiento fundados en aquello que conviene a los intereses dominantes más que en la situación real (Bauman, 2007: 47; Galbraith, 2011: 196-197; Bihr, 2017: 10).

Con todo, se observa por el lado de las políticas redistributivas - un pilar de la Cuarta Transformación- un cierto retorno al Estado

${ }^{11}$ En apenas seis meses, logró disminuir en 95 por ciento el robo de combustible e incrementar la producción de crudo, en caída desde la privatización (Pemex, 2019). 
como símbolo de lo común y como administrador de la justicia. Evidencia de ello son el incremento en un 16 por ciento al tan diminuto y devaluado salario mínimo, el aumento al doble de la escuálida pensión que recibían los adultos mayores y la garantía, mediante ambiciosos programas de becas, que ningún joven abandone sus estudios de bachillerato y universidad. En rigor, dicha redistribución está sujetada a la "proporción geométrica" entre las distintas clases, para decirlo en palabras de Cassirer (1997: 82). Es prudente, en razón de la vigilancia de los mercados financieros y de la dependencia comercial con Estados Unidos (dado que cerca del 80 por ciento de las exportaciones mexicanas llega allî). Como lo advertía José Martí, el influjo excesivo de un país en el comercio de otro se muda en influjo político (Funes, 2014: 133; El Economista, 2018). En verdad, México no dispone de mucha autonomía dada la desigualdad en recursos económicos, tecnológicos o militares en comparación con su vecino del Norte.

Según ha venido repitiendo López Obrador, la redistribución participaría del restablecimiento de la seguridad pública. Abatiría la creciente violencia y delincuencia, para las cuales la pobreza y la marginación son un terreno propicio (Morena, 2018/a). Pero los pobres y los marginados son también los más afectados por la inseguridad. Incluso las tecnologías de vigilancia, que supuestamente protegen a todos, fomentan las desigualdades y generan dinámicas de exclusión (Arteaga Botello, 2018: 29 y 54). Sufren en mayor grado los atropellos a los derechos humanos perpetrados por las fuerzas policiacas y militares (Castro Domingo, 2008: 60): feminicidios, desapariciones por decenas de miles como aquellas de los 43 normalistas de Ayotzinapa ${ }^{12}$. A pesar de todo, López Obrador autorizó la creación de una Guardia Nacional. (Adscrito a la Secretaría de Defensa, este cuerpo castrense de élite cuenta con sesenta mil

12 A finales de septiembre de 2014 la policía persiguió y atacó a estudiantes de la Escuela Normal Rural de Ayotzinapa (estado de Guerrero), a quienes acusaban de haber protestado y tomado de forma ilegal autobuses en la terminal local. Los hechos dejaron un saldo de al menos 9 personas fallecidas, 27 heridos y 43 estudiantes desaparecidos. 
elementos). La frontera entre seguridad pública y nacional sigue siendo tenue. No se modifica el desequilibrio entre cuidado y control que se estableció bajo el sexenio Calderón (2006-2012). (Intentando legitimarse después del fraude electoral que lo condujo a la presidencia, el mandatario panista recurrió a las Fuerzas Armadas para combatir la delincuencia organizada. Sin embargo, el proceso de militarización del país no era inédito: en los diez años anteriores el número de soldados aumentó en un cincuenta por ciento). (Castro Domingo, 2008: 47; Calderón Rodríguez, 2011: 184).

\subsection{La limitada descorporativización ${ }^{13}$}

En el corporativismo, el poder político se impone a la ley con el fin de alcanzar sus objetivos (Dautrey, 2017: 67). Fue justamente para imposibilitar esta práctica por lo que el nuevo gobierno refrendó la división de los poderes y la independencia de los órganos autónomos como la Comisión Nacional de Derechos Humanos y el Instituto Nacional Electoral (Morena, 2018/a). De esta forma, respaldó la garantía de las libertades fundamentales y la facultad para elegir y ser elegido. Están en el orden del día la instauración de un Estado de derecho y el fin a la represión contra la movilización social y la oposición política. Una señal clara fue la liberación de 16 presos a principios de 2019 y la revisión de otros 352 casos referentes a ambientalistas y a opositores a la ya cancelada reforma educativa neoliberal.

No obstante, la cuestión de la ampliación de la ciudadanía determinada por derechos queda pendiente. Una jerarquía tácita permanece. En lo alto de la pirámide, se encuentran los grupos que no necesitan un intermediario para hacer respetarlos. Por debajo de ellos, están los asalariados del sector formal protegidos por la justicia del trabajo y poseedores de beneficios sociales a través de los sindicatos oficiales. Aún más abajo, se abre el universo del sector informal y de los marginados. Ellos suelen recurrir al mediador. Son presas del clientelismo y del reparto selectivo de esos beneficios (Dautrey, 2013 y

13 Sobre este concepto véase Dautrey, 2017. 
2017). En resumen, la igualdad jurídica no es asegurada para todos y depende de los objetivos del momento del poder político. Se perpetuó el esquema vertical corporativista y una percepción pragmática sobre el vínculo con las instituciones (Castro Domingo, 2008: 207, 210 y 244). Solo un Estado imparcial faculta la universalidad de los derechos en virtud de mecanismos independientes y no discrecionales. Uno que asegura la igualdad de todos ante la ley y también mediante ella (Schnapper, 2004: 27; Rouquié, 2011: 340).

La cuestión del combate a la corrupción, cuya erradicación constituye otro pilar de la Cuarta Transformación ${ }^{14}$, representa un reto colosal. Según Transparency International (2019), en el sector público el índice de percepción de la corrupción era de 28 en 2018, ubicando a México en la posición 138 entre 180 países. Éste es la cuarta nación más impune a nivel global y la primera en América (Udlap, 2019).

Habiendo dicho esto, cierta descorporativización se está produciendo en la función pública. Mas el servicio profesional no forma parte de las tradiciones burocráticas del país, las cuales se basan en la lealtad a los jefes y en el intercambio de favores y privilegios. La alternancia no representó ningún cambio sino la extensión de las prácticas corruptas a los demás partidos ${ }^{15}$ (Zabludovsky Kuper, 2009: 84). Los criterios clientelistas y nepotistas marcaron de nuevo el reclutamiento de los funcionarios. Ahora, el aparato del Estado permanece poblado de partidarios del antiguo régimen. No se sienten obligados a la obediencia hacia un gobierno contrario. Ante esta situación, López Obrador envió al Parlamento una iniciativa de ley para sancionar de manera más severa a los servidores públicos por nepotismo. Se suprimió el fuero de los altos funcionarios y se redujeron sus salarios. En lo sucesivo no podrán rebasar el del presidente de la República (Morena, 2018/a). Asimismo, se canceló las enormes pensiones a los ex presidentes y se desmanteló la parafernalia

${ }^{14} \mathrm{La}$ corrupción, funcional al corporativismo, reduce las inversiones y genera un crecimiento económico más lento (Castro Domingo, 2008: 208).

${ }^{15}$ La Ley del Servicio Profesional de Carrera del 2003 contemplaba un tipo de servicio civil con un reclutamiento y una promoción sustentados en el mérito, pero sus alcances resultaron limitados 
del poder (venta de los aviones y helicópteros particulares igual que del suntuoso avión presidencial, cancelación de los seguros de gastos médicos, desaparición del Estado Mayor Presidencial, de más de 6000 efectivos). Además, los recursos que se rescaten de los políticos corruptos, y de la delincuencia organizada, serán entregados a los municipios para realizar obras públicas o se destinarán a escuelas, centros de salud y asilos de ancianos. En la misma tónica, una ley recién aprobada obliga a las dirigencias sindicales a rendir cuentas. El propósito es desestimular la apropiación indebida del patrimonio de las organizaciones oficiales y asegurar la transparencia en el manejo de las cuotas y las finanzas. Se incluyeron sanciones en caso de no cumplimiento. En nombre de la lucha contra el clientelismo, la nueva administración eliminó también a los mediadores que entregaban los recursos de los programas sociales. En su lugar nombró en cada estado de la república a un delegado de Programas Integrales de Desarrollo y puso en marcha un censo de los derechohabientes con el propósito de entregarles directamente los fondos y evitar los intermediarios o el traslado de dinero en efectivo.

Desde la perspectiva gubernamental, la eliminación de las dañosas prácticas del corporativismo participa de la subsanación de las cuentas públicas y de la redistribución de los recursos a los pobres y los excluidos. Máxime, se trata de consolidar el marco legal-racional sustituyendo la corrupción por mecanismos asentados en la normativa constitucional. Está en juego la instauración de un "deber ser", para decirlo así (Sartori, 2017: 14), destinado a hacerse realidad en una Constitución Moral. Hoy en día la urgencia reside en instituir una cultura de la legalidad y restaurar la confianza de la ciudadanía hacia las instituciones. (Un ejemplo: el porcentaje de delitos no denunciados no deja de aumentar dada la impericia de los cuerpos policiacos y judiciales). La corrupción y la impunidad no han de cumplir el papel de ordenadora de la sociedad (Morena, 2018/ay 2018/b; Udlap, 2019). Ser corrompido ha de resultar costoso. Ya se tipificó como delito grave. 


\section{Conclusión}

La Cuarta Transformación ambiciona antes que nada luchar contra la corrupción y ponerle freno a la deriva neoliberal de las últimas décadas. Tal como lo observó Bobbio (1986), la democracia es el gobierno de las leyes y no de los hombres. Su concretización supone el control de la corrupción y la descorporativización de toda la sociedad, así como la modificación de la Constitución autoritaria vigente. Pero López Obrador no contempla establecer una nueva sino adecuar el marco constitucional (Morena, 2018/a). En cuanto a la contención del neoliberalismo, implica una cuidadosa rehabilitación del Estado como reductor de incertidumbre. En efecto, la eliminación del pacto nacional popular e interclasista a principios de los años ochenta fracturó el tejido social y las desigualdades que resultaron de ello circunscribieron la democracia (Castro Domingo, 2008: 203; Dautrey, 2018: 86).

El cambio actual no solo se inscribe en una ética de la intención sino en una de la responsabilidad ${ }^{16}$. Por tanto, el nuevo gobierno plantea eludir el conflicto con el imperio - dado que no reivindica una soberanía en contra de un Otro representado por Estados Unidos- y con los poderes fácticos por lo que, para decirlo a la manera de Bauman (2001: 84), la agenda política se cristaliza como efecto ulterior de las operaciones de mercado: no las precede como intención u objetivo. Del mismo modo, procura componer relaciones con la periferia autoritaria (los estados gobernados principalmente por el PRI y el PAN) y deja pendiente idear un federalismo que impida sus abusos (Rouquié, 2011: 311; Dautrey, 2017: 71).

Se puede hablar de transición en el sentido de que las elecciones del año 2018 se encaminaron a algo más que un canje del personal político. Llegó a la presidencia un partido cuyo proyecto se propone transformar las instituciones construidas a la medida por y para el dominio del PRI. A decir verdad, hay mucho por hacer y deshacer. En

16 Para Max Weber, la primera persigue el bien y la segunda tiene en cuenta las consecuencias de las acciones (Sartori, 2017: 81). 
todo caso, se requieren medios para sustentar dichas políticas ${ }^{17}$. Finalmente, la transición refuerza la confianza en la democracia y contribuye a la disminución de la humillación y del miedo que tanto instiló el régimen autoritario. Aunque no sean cruciales, esas emociones influyen el rumbo de la historia (Moïsi, 2008: 27-28). Son el fermento del apoyo popular que tanto necesita López Obrador para llevar a cabo la Cuarta Transformación. Siempre y cuando no se conviertan en expectativas impracticables. Como lo advirtió Elías (1997: 96), la fe en el poder ilimitado de algunos individuos únicos en su género es una utopía. En una sociedad como la mexicana en la que la cultura corporativista está tan enraizada, la instauración de una ciudadanía con plenos derechos sería en sí un avance significativo, pero esto no puede darse sino en forma paralela a la interiorización de una cultura política democrática (Rouquié, 2011: 339), con la que se llegaría a alcanzar una sociedad socialmente más justa y económicamente más eficiente. Mientras tanto, por el momento la sombra del autoritarismo parece alejarse.

\section{Bibliografía}

Arteaga Botello, N. (2018). Video vigilancia en México (protesta politica, conflicto y orden social). México: Facultad Latinoamericana de Ciencias Sociales.

Babb, S. (2003). Proyecto: México (los economistas del nacionalismo al neoliberalismo). México: Fondo de Cultura Económica.

Bartra, R. (2005). La jaula de la melancolía (identidad y metamorfosis del mexicano). México: Debolsillo.

\footnotetext{
17 La fiscalidad es decisiva. En la actualidad, la carga fiscal es baja (un 16,2 por ciento) en relación con su Producto Interno Bruto y los niveles de evasión físcal son todavía altos (un 2,6 por ciento del Producto). El Sistema Tributario Nacional es incapaz de alcanzar los niveles de recaudación de ingresos que requieren las entidades federal, estatal y municipal para hacer frente a sus obligaciones de gasto (SAT, 2017: 4; OECD, 2018). Por si fuera poco, los impuestos tienen una escasa eficacia redistributiva. Por su parte, la corrupción explica tanto la evasión como el rechazo al impuesto (Dautrey, 2018: 88).
} 
Basave, A. (2011). Mexicanidad y esquizofrenia (los dos rostros del mexijano). México: Océano exprés.

Batres Guadarrama, M. (2017). El desastre del PRLAN: hacia la superación de la falsa alternancia. México: Grijalbo.

Bauman, Z. (2001). En busca de la política. Buenos Aires: Fondo de Cultura Económica de Argentina.

Bauman, Z. (2007). La sociedad sitiada. México: Fondo de Cultura Económica.

Bihr, A. (2017). La novlangue néolibérale (la réthorique du fétichisme capitaliste). Paris/Lausanne: Syllepse/Page 2.

Bobbio, N. (1986). El futuro de la democracia. México: Fondo de Cultura Económica.

Caillé, A. (2009). Théorie anti-utilitariste de l'action (fragments d'une sociologie générale). Paris: La Découverte (textes à l'appui)/bibliothèque du mauss.

Calderón Rodríguez, J. M. - coordinador - (2011). América Latina. Estado y sociedad en cuestión. México: Universidad Nacional Autónoma de México.

Cappello, H. M.; y De Pedro Robles, A. E. (2010). Historia, identidad nacional y carácter cívico-político en sociedades complejas (el caso de las sociedades española y latinoamericana). México: Plaza y Valdés Editores/Universidad Autónoma de Tamaulipas.

Cassirer, E. (1997). El mito del Estado. México: Fondo de Cultura Económica.

Castro Domingo, P. - coordinador - (2008). Procesos políticos contemporáneos. México: Consejo Nacional de Ciencia y Tecnología/Universidad Autónoma Metropolitana/Universidad Autónoma del Estado de México/Miguel Ángel Porrúa.

Dautrey, P. (2013). "Precariedad de la sociedad, segmentación de la política social: el caso de México". Revista Europea de Estudios Latinoamericanos y del Caribe, núm. 94, pp. 23-40.

Dautrey, P. (2017). "Diferenciación funcional y régimen político en México: entre reacomodo y continuidad". Rivista Visioni Latino Americane, núm. 16, pp. 63-80.

Dautrey, P. (2018). "Mutaciones de la sociedad y cohesión social. El caso mexicano". Diálogos Latinoamericanos, vol. 19, núm. 27, pp. 80-92

El Economista (2018). Crecen las exportaciones de México hacia EU. 
https://www.eleconomista.com.mx/economia/Crecen-las-exportacionesde-Mexico-hacia-EU-20180814-0031.html. 14 de agosto.

Elias, N. (2017). La société des individus. Paris: Fayard.

Fernández, A.; y Lesgart, C. - compiladores - (2008). La democracia en América Latina (partidos politicos y movimientos sociales). Rosario/Santa Fe (Argentina): Homo Sapiens Ediciones.

Fernández Liria, C.; García Fernández, O.; y Galindo Ferrández, E. (2017). Escuela o barbarie (entre el neoliberalismo salvaje y el delirio de la irquierda). Madrid: Ediciones Akal (Pensamiento crítico).

Funes, P. (2014). Las ideas políticas en América Latina. México: El Colegio de México.

Galbraith, J. K. (2011). Historia de la economia. Barcelona: Editorial Ariel.

Garay Salamanca, L. J.; y Salcedo-Albarán, E. (2012). Narcotráfico, corrupción y Estados (cómo las redes ilícitas han reconfigurado las instituciones de Colombia, Guatemala y México). Bogotá: Random House Mondadori.

González Gómez, F.; y González Gómez, M. A. (2007). Del porfirismo al neoliberalismo. México: Ediciones Quinto Sol.

Guillén Romo, H. (2005). México frente a la mundialización neoliberal. México: Ediciones Era.

Instituto Nacional Electoral - INE - (2018). Da a conocer INE resultados del cómputo de la elección presidencial 2018.

https://www.centralelectoral.ine.mx/2018/07/06/da-conocer-ineresultados-del-computo-de-la-eleccion-presidencial-2018/, 6 de julio.

Mascareño, A. (2010). Diferenciación y contingencia en América Latina. Santiago de Chile: Ediciones Universidad Alberto Hurtado.

Merino, M. (2003). La transición votada (crítica a la interpretación del cambio politico en México). México: Fondo de Cultura Económica.

Moïsi, D. (2008). La géopolitique de l'émotion. Paris: Flammarion (Champs actuel).

Movimiento Regeneración Nacional - Morena - (2011). Proyecto de Programa MORENA.

https://www.lopezobrador.org.mx/programa-del-movimientoregeneracion-nacional/, año 2011.

Parlamentario Senado MORENA, LXIV Legislatura.

$(2018 / a)$

Grupo

https://www.Morena.senado.gob. $\mathrm{mx} / 2018$ /12/ 01/hoy-se-instaura-lacuarta-transformacion-de-la-republica-el-grupo-parlamentario-deMorena-en-el-senado-refrenda-su-apoyo-al-presidente- 
constitucional-de-los-estados-unidos-mexicanos-andres-manuel-lo/, 1 de diciembre de 2018. (2018/b). López Obrador convoca a los mexicanos a participar en la elaboración de la Constitución Moral para una nueva República.

https://www.lopezobrador.org.mx/temas/constitucion-moral/, 26 de noviembre (2018/c), Presidente electo presenta programa Sembrando Vida que reactivará el sureste mexicano.

https://www. lopezobrador.org.mx/2018/10/08/presenta-amlo-beneficiosdel-programa-sembrando-vida/.

Organization for Economic Co-operation and Development - OECD (2018). Tax revenues continue to increase in the OECD.

https://www.oecd.org/tax/tax-policy/revenue-statistics-2522770x.htm.

Osorio, Jaime (2004). El Estado en el centro de la mundialización (la sociedad civily el asunto del poder). México: Fondo de Cultura Económica.

Petróleos Mexicanos - Pemex - (2019). Disminuye 95 por ciento el robo de combustible en México, e incrementa producción de crudo.

http://www.pemex.com/saladeprensa/boletines nacionales/Paginas/2019014-nacional.aspx.

Polanyi, K. (2001). La gran transformación (los orígenes politicos y económicos de nuestro tiempo). México: Fondo de Cultura Económica.

Rouquié, A. (2011). A la sombra de las dictaduras: la democracia en América Latina. Buenos Aires: Fondo de Cultura Económica.

Sartori, G. (2017). La carrera hacia ningún lugar (diez. lecciones sobre nuestra sociedad en peligro). México: Taurus.

Schnapper, D. (2004). La democracia providencial (ensayo sobre la igualdad contemporánea). Rosario-Santa Fe: Homo Sapiens Ediciones.

Servicio de Administración Tributaria - SAT - (2017). Evasión global 2017.

http://omawww.sat.gob.mx/administracion sat/estudios evasion fiscal/D ocuments/Evasionglobal2017.pdf.

Therborn, G. (2014), ¿Del marxismo al posmarxismo? Madrid: Ediciones Akal.

Transparency International (2019). Corruption perceptions index 2018, https://www.transparency.org/cpi2018.

Touraine, A. (1995). ¿Qué es la democracia?. México: Fondo de Cultura Económica. 
Universidad de las Américas Puebla -Udlap- (2019). Indice Global de Impunidad México 2018 vía UDLAP.

https://imco.org.mx/temas/indice-global-impunidad-mexico-2018-viaudlap/.

Zabludovsky Kuper, G. (2009). Intelectuales y burocracia (vigencia de Max Weber). Barcelona: Anthropos Editorial. 